\title{
Applied Research on Training Children's All-round Abilities in Nature Education
}

\author{
Yang Yan ${ }^{1, *}$, Li Shuai $^{1}, \mathrm{Li} \mathrm{Yi}^{2}$ \\ ${ }^{1}$ School of Ecology Technology and Engineering, Shanghai Institute of Technology, Shanghai, 201418, China \\ ${ }^{2}$ Zhuosheng (Shanghai) Agricultural Technology Co., Ltd.)
}

\begin{abstract}
Economic development and the expansion of cities have added to the tension between human and nature, and intensified the conflicts among human, nature and the society. Urbanization has narrowed the gap between human communities, but widened the distance between human and the natural world. Against this backdrop, the term "natural deficiency" came into being. This term was first proposed by the American scholar Richard Louv in 2008 in his book "The Last Child in the Forest", indicating that children had long been cut off from the nature and nature had been reduced to a mere imagination. A survey report on the intimacy between urban children and nature released by a research center in Shanghai in 2013 pointed out that "out of the more than 1,300 children surveyed, over 150 children have natural deficiencies. The tendency is mainly manifested as: inability to concentrate, inability to blend into the environment quickly, and lack of curiosity about the natural world." The reasons for this symptom are mainly twofold: first, in the information age, children are so attached to a slew of electronic products such as mobile phones and computers that few prefer to spend time outdoors; secondly, the prevalence of off-campus training classes has robbed the children of time to go to parks and natural scenic spots where they can be exposed to the natural environment. Nature education can combine classroom teaching with natural activities to effectively narrow the distance between people and nature.
\end{abstract}

\section{Introduction}

\subsection{National demand for talents}

In today's world, education plays an important role in our life. Preschool education, taking place in tender years, plays a critical role throughout one's life. Encouraging pre-school or early childhood education is a major livelihood project that $\mathrm{CPC}$ and the government initiates to improve people's life. This strategy can promote social harmony and stability, and facilitate China's other livelihood endeavors. At home, family education is also extremely important. Family education also plays a critical role in children's growth; for instance, parents can work together with teachers to help their kids' complete homework. Surveys show that more than $80 \%$ of parents in China have registered for their children to participate in a variety of off-campus training classes.

Preschool education plays an important role in shaping one's character when they grow up. As a Chinese saying goes, "A child shows his childhood character at three years old, and his life-long personality when turning to seven". This saying reveals the psychological development of a child. The time before the age of three is a critical period for children's brain development. Before age three, children are thirst for knowledge, and are easily affected by their parents' words, behaviors and habits. Thus, parents should seize this time and develop their kids' potential. The Chinese classic Three-Character Scripture reads "if one does not learn at an early age, he will be a loser when growing up". The famous American psychologist Bloom found through a long-term study that the fastest period of children's intelligence development is from birth to five years old. If one considers the intelligence level of a person at the age of 17 as 1 , then the child has already obtained 0.5 before the age of 4 , and $30 \%$ of the remaining 50\% was obtained between 4 and 7 years old; and the rest $20 \%$ was obtained from 7 to 17 years old. Therefore, the time before 7 years old deserves special attention from the children's parents. Nowadays, investment into early childhood education is increasing, and training of talents in tender years has drawn wide attention in the society. At the National Education Conference, General Secretary Xi Jinping emphasized: "cultivating people is the priority of education", "the fundamental task of education and the direction of efforts to modernize education." The most distinctive theme of the era in China today is to achieve the Chinese dream of the great rejuvenation of the Chinese nation. Therefore, we should take "cultivation of talents" as the priority of education to achieve creative development. Therefore, to train students in an all-round manner is important in children's education.

\subsection{The importance of talents}

* Corresponding author: 693483030@qq.com 
The diverse fields of social services require talents of diverse skills. The society's requirements for talents' abilities differ as time moves forward: in the agriculture age, the prioritized ability is the ability to respond to natural challenges and access to as many resources as possible to survive. In the industry age, the prioritized ability is the ability to collaborate. In the postindustrialization age featured by high complexity and high uncertainty, the required abilities are beyond the abovementioned two, such as the ability to cooperate, the ability to achieve win-win.

In addition, there are such abilities as practical ability, innovation ability, learning ability, thinking ability, pronature ability, exploration ability, etc. These abilities play an important role in human growth and development.

\subsection{Ability development stage}

The growth of abilities is closely related to one's age, but most of the abilities can be cultivated in early childhood, a stage that plays a critical role in shaping a person's characters and habits. This stage of education plays a decisive role in the growth of young children. Therefore, early childhood education should be highly valued by parents and kindergarten teachers.

Today, with the development of science and technology, early childhood education has also developed and gained more support from parents and teachers. Cultivation of various abilities in early childhood not only lays a foundation for further development of children's qualities, interests and hobbies, but also establishes a sound personality of young children. Therefore, early childhood education is closely correlated to healthy growth of children and nature education is an important part of early childhood education.

\subsection{Training model of children's abilities}

Early childhood plays a decisive role in one's future development. As the foundation stage of lifelong education, early childhood education is still based on classroom teaching and cultural knowledge training, most of which are indoor activities such as training camps, classroom education, parent-child activities. Due to the influence of traditional Chinese educational philosophy, pre-school education is largely utilitarian and education that violates the nature of children abounds. Adults occupy an absolutely dominating position in education. Wishful thinking that early education can prevent children from losing at the starting line.

How to properly guide children and release their children's instincts, while at the same time developing their abilities is a concern of many parents. Through investigation and research, it is found that children's longing for the natural world is higher than for indoor lecturing. However, due to limitations in venues, funding, and safety, it is inconvenient and impractical to lead the children out of the classroom and carry out outdoor teaching activities. It is advisable we introduce nature into the kindergarten classroom, let the children actively observe and appreciate the beautiful gardens, Experience, explore, perceive, create, and initially form a good environmental morality, values and behaviors.

As the population grows and the environmental problems exacerbate now, China has few places to provide children with fun and enjoyment. Taking into account the safety of young children, forest education is nothing more than mere daydreaming. In view of such a situation, "natural corners" created by small-volume natural scenes came into being and engaged children in gardening activities at a corner of the campus, thereby allowing them to bond with nature and absorb the power of growth from nature. Gardening, which is a combination of art and science and nature, provides a series of things that engage children with nature: vitality, flowers, housework Body, outdoor exploration, practical ability, discovery ability, aesthetic ability, spatial thinking, even music nurturing, character development, etc.

It is imperative for kindergartens to promote nature education. While receiving nature education, children fully develop their feelings, linguistic capacity, independent thinking, participation, communication and cooperation, which can promote the comprehensive and harmonious development of children's body and mind. Nature education should be carried out in various ways according to local conditions.

\subsection{Connotation of nature education}

"Nature education" is based on the natural environment, using humans as the medium, using scientific and effective methods to integrate children into nature, and using systematic means to achieve the effective collection and sorting of children's information to form an effective social life. Effective nature education should follow the three principles: integration, system and balance. In terms of the form of education, nature education is a form of education in which nature is the teacher. Nature education should have a clear educational purpose, a reasonable educational process, and measurable educational results, to achieve an effective connection between children and nature, and thus maintain children's intellectual growth, physical health and mental development.

The contemporary educationist Tao Xingzhi proposed the idea of "six liberation": liberating children's minds; liberating children's hands; liberating children's eyes; liberating children's mouths; liberating children's space; liberating children's time. These "six liberation" ideas have important guiding significance for ability education. It is of great importance to follow the "six liberation" ideas in early childhood education, reduce the constraints on young children, release the nature of young children, and allow young children to learn to feel the surroundings and experience nature.

The "Kindergarten Education Guidance Outline" clearly states that kindergartens should encourage children to love animals and plants, care about the 
surrounding environment, be close to nature, cherish the beautiful emotions of natural resources, and develop a preliminary environmental awareness. The environment is an important educational resource which can be made the best use of to expand the space for young children to live and learn. Children's understanding of nature is based on their love for nature. The stronger the love is, the deeper the understanding is. To this end, in nature education, we focus on stimulating children's love of nature and their desire to care for the environment.

The systematic nature education of children can alleviate this problem. In this paper, through case studies, a survey of a number of kindergartens initiated by Nature Corner in Shanghai revealed that most children have significantly improved their language expression ability, hands-on ability and innovation ability in nature education activities.

\section{Facilities and related courses for children's ability development}

Kindergartens play an important role in children's education. It is extremely important for children's growth to reasonably set up kindergarten facilities and develop curriculum.

\subsection{Reasonable layout and construction of the natural corner}

Taking Longhua Kindergarten in Xuhui District as an example, the natural corner of Longhua Kindergarten has currently set up with a small farm. In view of the complex outdoor situation, according to local conditions, landscape natural corners of different sizes are set up, and a unique ecological warm shed is configured. After rational interior design, simple fungus racks, solid wood flower stands, greenhouse fruit growing boxes and other facilities have been installed. Teachers can make full use of these facilities to guide children to bond with nature.

\subsection{Linked nature education curriculum}

In the spring of this year, the park organized a spring tour with the theme of "Footsteps of Spring". First, children played in the natural corner of the campus to cultivate their pro-natural abilities. Secondly, they were encouraged to discover the elements related to the arrival of spring, discover the beauty of spring from experiences such as "listening, feeling, watching", and develop young children's abilities to discover and appreciate beauty. These activities cultivated the kids' observation ability, exploration ability and art appreciation ability, Kids are fully engaged in these activities, encouraged to sow seeds and harvest fruits in autumn, and developed their hands-on skills. In group work, children's organizational and collaboration abilities were cultivated. After returning to the classroom, children were encouraged to discuss in groups the activities in the natural corner to stimulate their creative thinking, their research and discussion abilities, imagination and learning ability; finally, each group chose a representative to share their feelings about spring in front of the class. In this way, children's abilities in language expression ability and role model demonstration were cultivated (Figure 1).

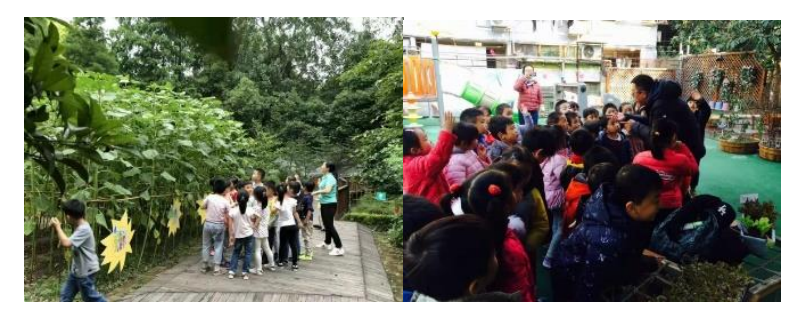

Figure 1: Natural education courses

Children were required to maintain the facilities in the corner, such as the flower stands and planting boxes, under the simple guidance of the teacher; Also, they needed to water the potted plants every day, take them out to shower the sun every morning, etc., which would cultivate the children's sense of discipline, self-care ability and imitation ability. Throughout this process, children's emotional perception and cognitive development were enhanced.

\subsection{Analysis of the situation of nature education on children's ability development}

Kangtai Kindergarten is located in Putuo District, Shanghai. The small balcony on the second floor of the garden has always been used as a venue for outdoor activities. After discussion, it was transformed into a roof planting area. Before the renovation, it was managed by the kindergarten staff in the garden and was not be used reasonably. During the investigation of the current situation, the author learned that very few children have approached or observed the growth of plants in this garden.

In the actual transformation of the garden, the shape of the Tetris planting box was creatively used. The planting box can be designed into different styles to carry out Tetris game activities, increasing the landscape and fun of the area. After this, the children gradually developed a deep observation and understanding of the plants in the planting box through the activities in the physical education classroom, and thus interact with nature. A plant labyrinth was creatively created to add to the fun and interest of education.

Since the start of the nature education in Kangtai Kindergarten, the author has been taking records of the education effect. Experiments during the nature education were performed among the children. After the implementation of nature education for one semester, 155 children in the middle class were compared and evaluated before and after participating in the activities, and an evaluation questionnaire was developed to assess the children's knowledge of nature, their diverse abilities, and their emotional and attitude changes. In order to display data more intuitively, this quantitative evaluation adopts a hierarchical system, which is divided into three levels: A (excellent), B (good), and C (average). 


\section{(1) Comparison of children's knowledge and learning}

Table2.1 Comparison table of children's knowledge and experience before and after nature education (percentage)

\begin{tabular}{ccccc}
\hline project & Time & Excellent & Good & General \\
\hline Natural knowledge & 2019.09 .15 & $66.45 \%$ & $21.29 \%$ & $12.26 \%$ \\
learning & 2019.12 .03 & $81.93 \%$ & $16.13 \%$ & $1.94 \%$ \\
\hline
\end{tabular}

Table 2.1 shows that $66.45 \%$ of children had excellent knowledge of nature when they first attended school, $21.29 \%$ performed well, and $12.26 \%$ performed generally. After the implementation of nature education for one semester, the number of children rated as "excellent" increased significantly, while those rated "good" and "average" decreased significantly. On the whole, these children were outstanding in learning knowledge of nature, and followed the guidance of teachers, but a few still needed improvement.

(2) Comparison of the development of children's allround abilities

The development of children's abilities is the main content of this study. We mainly selected several aspects that have a greater impact on children's growth for comparison. There are three aspects of comparison of children's abilities: autonomous observation ability, hands-on operation ability, and innovation and creativity, as shown in Table 2.2.

Table 2.2 Comparison of children's multiple abilities before and after nature education (percentage)

\begin{tabular}{lcccc}
\hline \multicolumn{1}{c}{ project } & Time & Excellent & Good & General \\
\hline Autonomous & 2019.09 .15 & $70.32 \%$ & $12.91 \%$ & $16.77 \%$ \\
observation & 2019.12 .03 & $80.00 \%$ & $18.06 \%$ & $1.94 \%$ \\
Hands-on & 2019.09 .15 & $74.19 \%$ & $16.13 \%$ & $9.68 \%$ \\
capability & 2019.12 .03 & $85.16 \%$ & $7.74 \%$ & $7.10 \%$ \\
& & & & \\
$\begin{array}{l}\text { Innovation and } \\
\text { creativity }\end{array}$ & 2019.09 .15 & $63.23 \%$ & $13.55 \%$ & $23.22 \%$ \\
\hline
\end{tabular}

Table 2.2 shows that the development of children's multiple abilities mainly covers three aspects: autonomous observation ability, hands-on operation ability and innovation and creativity ability. It can be analyzed that among 155 middle-class children participating in this evaluation, at the beginning of the semester, $70.32 \%$ showed outstanding observation performance, and only $16.77 \%$ were rated "average"; in terms of hands-on operation ability, $74.19 \%$ of the children performed well, $16.13 \%$ of the children performed well, and $9.68 \%$ performed generally; in terms of innovation and creativity, the proportion of children rated "excellent" was much smaller than that of those rated "excellent" in terms of independent observation and hands-on operation. Therefore, teachers should devote more to inspiring children's innovation and creativity skills. At the end of the semester, when the assessment was conducted, the number of children rated "excellent" in these three categories increased, and that of children rated "average" decreased markedly. On the whole, nature education has improved children's abilities.
(3) Comparison of children's emotional attitude before and after nature education

Table 2.3 Comparison of children's emotional attitude before and after nature education (percentage)

\begin{tabular}{lcccc}
\hline \multicolumn{1}{c}{ project } & Time & Excellent & Good & General \\
\hline Interest input & 2019.09 .15 & $65.81 \%$ & $22.58 \%$ & $11.61 \%$ \\
Sense & 2019.12 .03 & $85.16 \%$ & $14.84 \%$ & 0 \\
responsibility & 2019.09 .15 & $56.13 \%$ & $28.39 \%$ & $15.48 \%$ \\
& 2019.12 .03 & $82.58 \%$ & $15.48 \%$ & $1.94 \%$ \\
Sharing & & & & \\
awareness & 2019.09 .15 & $59.35 \%$ & $29.03 \%$ & $11.62 \%$ \\
\hline
\end{tabular}

By comparing children's emotions and attitude before and after nature education, we can see that after a semester of nature education, through interest input, sense of responsibility, and awareness of sharing have been significantly improved, more and more children were rated "excellent", and some who used to be rated "good" had developed to the "excellent" level; and only a few children still stayed at the "average" level.

In summary, as mentioned in the contents of the three tables, children have significantly improved in learning knowledge, the development of various abilities, emotions and attitudes after a semester of nature education. In addition to the improvement of their own physical qualities, their psychological and physiological qualities have been correspondingly improved. Among the 155 children in the middle class, $80 \%$ were rated "excellent" after nature education. Only a few children need to work harder. During the activities, the children's own qualities have been comprehensively improved, which stimulated the children's interest in learning and enhanced their intellectual development and encouraged them to communicate with each other.

In the same way, we have obtained similar research results by creating natural corners and outdoor activities in the Xuhui District Yuyu Kindergarten, Yisi Kindergarten, Putuo District Long March Center Kindergarten, and East China Normal University Affiliated Kindergarten.

\subsection{Results and discussion}

In 2017-2018, the author's research team conducted a one-year experiment of nature education for more than 500 children in the abovementioned five kindergartens, and developed a small-class nature education course based on cognition, mainly for expression, for children of different grades, the middle-class nature education courses and the inquiry-based large-class nature education courses. During the experiment, children showed a strong interest, and most children were able to follow the teacher's footsteps to learn seriously.

The natural classroom was set up to lead small-class children to recognize the animals and plants on the campus. After three courses (once a week), $60 \%$ of the small-class children could simply match the photos and names with the animals and plants in the kindergarten. Children in the middle class could accurately describe the distinctive characteristics of the animals and plants. 
The large-class children, after taking the small experiment of apple power generation, could already do it themselves. They found that common fruits such as lemons, oranges, pineapples, could also generate electricity.

Experiments have shown that through long-term outdoor nature education activities, children's practical skills, language expression ability, and imagination outperformed other children that had not received nature education of the same age.

Table2.4: Questionnaire summary

\begin{tabular}{ccccc}
\hline & total & valid questionaire & $\begin{array}{l}\text { Support } \\
\text { questionnaire }\end{array}$ & $\begin{array}{l}\text { Reserved opinion } \\
\text { questionnaire }\end{array}$ \\
\hline teacher & 45 & 42 & 35 & 7 \\
Parents & 90 & 75 & 63 & 5 \\
\hline
\end{tabular}

By sorting the 45 questionnaires of kindergarten teachers ( 3 for each kindergarten and 3 grades each year), 35 of them think that children show great enthusiasm and interest; some teachers believe that this kind of nature education based on local conditions is better than conventional video-based teaching, more practical and more worthwhile to be promoted.

According to the analysis of 90 questionnaires of children's parents, most of the parents believe that the children's abilities have been significantly improved. The children have become more lively, willing to approach nature, and more diligent, and more eager to learn new knowledge.

Practice has proved that nature education could improve children's essential life abilities, such as handson skills, cognition, inquiry, and cooperation, and it has a certain impact on children's thinking style.

The society is constantly developing, and educational reforms have always been on the way. Nature education in kindergartens is committed to harmonizing children with nature and society and promoting their psychological harmony and unity. Nature education aims to cultivate children's environmental awareness, encourage them to cherish nature, protect the environment, and develop eco-friendly habits. This study can enrich the theories of the preschool curriculum development in China through the construction of the preschool curriculum of nature education and determine the purpose, content, implementation and evaluation of the curriculum, and then facilitate future studies on preschool nature education in China. In preschool education, we should summarize the law of children's needs for development, strengthen the students' perception of nature and life by exposing them to the nature, let them experience the beauty of nature and achieve long-term development.

\section{Conclusion and prospect}

This paper explores the status quo of nature education in kindergartens in China. In the study, the authors asked questions, identified research problems, found solutions and proposed suggestions, with a view to provide a theoretical basis for future studies on preschool nature education. The paper first explains the background and significance of the research, studied different preschool course design in China and abroad through literature review, and conducted case studies in kindergartens. Through systematic analysis, in-depth discussion and interpretation of causes for the current situation of preschool nature education in China, this study proposed suggestions for design of nature education courses for kindergartens and aimed to provide a complete set of theories in this regard. The impact of application of nature education in kindergartens was also explored via case studies to deepen the understanding of the status quo and prospect of preschool nature education in China. Secondly, by combining theories with practice, the authors explored the goal, content, implementation and evaluation of the nature education curriculum, which enriched the nature education research system. Creating a system of nature education that can be widely promoted will facilitate future reforms in early childhood education.

\section{References:}

1. Liu Shilin. The globalization process of urban agglomerations and China's experience [J]. Academics, 2012 (06).

2. $\mathrm{Xu}$ Qin. The development of the Yangtze River Delta under the multi-center structure [J]. Modern Economic Research, 2018 (09)

3. Luigi T. Zhu Yingming. Study on the Regional Structure Characteristics and Development Trend of Urban Agglomerations in China[J]. Urban Planning Journal, 2001, (7): 55-57)

4. QianHuixiong. Measurement of Regional Economic Integration in the Yangtze River Delta Region [J]. Finance and Trade Research, 2010(5)

5. Ren Zhenzhu. The Future of the Yangtze River Delta: Opportunities and Challenges [M]. People's Publishing House, August 2011 